\title{
Are Spillover Effects Between Oil and Gold Prices Asymmetric? Evidence From the COVID-19 Pandemic
}

\author{
Wenli Huang', Mian Wu' \\ ${ }^{1}$ China Academy of Financial Research, Zhejiang University of Finance and Economics, China \\ Keywords: gold price, oil price, spillover effect, covid-19 \\ https://doi.org/10.46557/001c.28127
}

Energy RESEARCH LETTERS

Vol. 2, Issue 4, 2021

Our research explores how the COVID-19 pandemic has influenced the asymmetric spillover effects in the oil and gold markets. Through a VAR(p)-BEKK-AGARCH(1,1) model fitted to daily gold and oil price data, 1) we find evidence of spillover only from the oil to the gold market and that this effect is stronger during the pandemic and 2) we conclude that a negative information shock in the oil market has a larger impact on gold return volatility compared to a positive shock and that this asymmetric spillover effect intensified during the pandemic.

\section{Introduction}

Changes and co-movement in gold and oil prices have always been the subject of worldwide attention. According to Shahbaz et al. (2017), there has been a positive price correlation between gold and oil prices more than $80 \%$ of the time in the past 50 years. The economic recession caused by the COVID-19 pandemic and unsuccessful trade negotiations between Russia and the Organization of the Petroleum Exporting Countries have led to a dramatic drop in West Texas Intermediate (WTI) crude oil prices (Atri et al., 2021). Uncertainty has always driven investors to seek safer assets, particularly gold. Many studies have demonstrated the safe haven property of gold (Baur \& McDermott, 2010; Dutta et al., 2020; Reboredo, 2013; Salisu et al., 2021). As seen in Figure 1, the price of gold has witnessed a mild rise since March 2020, despite the decline in mid-March.

Only a few studies have investigated the nexus between gold and oil prices, with the majority examining the mean and volatility spillovers between the returns of these two assets (Bampinas \& Panagiotidis, 2015; Chen \& Qu, 2019; Gharib et al., 2021). The spillover effect refers to the phenomenon where a large information shock increases the return correlation not just in the market in question, but also in other markets. Mean spillovers are also shown to be time varying. According to Yaya et al. (2016), the spillover effects between gold and oil prices disappeared after 2008, with only one-way spillover from gold to oil prices remaining. Using daily exchange-traded fund (ETF) prices of gold, silver, oil and global equity, Lau et al. (2017) show that the previous week's information contributes to the transmission of oil and gold return spillovers between the gold and oil markets. Studies have also found that the volatility spillover effect differs over time. For instance, Kang et al. (2017) find more pronounced volatility spillovers across commodity futures markets, including oil and gold, in postcrisis periods, including the global financial crisis (from November 23, 2007, to May 22, 2009) and two European debt crises (from November 5, 2009, to April 22, 2010, and from
May 2, 2011, to May 30, 2012).

Despite the above-mentioned works, relatively little is known about the asymmetry and direction of spillover effects between the oil and gold markets. Ross (1989) argues that asset returns would induce different volatility patterns and spillover effects, since the information innovation and processing times vary across markets. Asymmetric reactions in information shocks between pairs of assets are more common today, and understanding their possible implications will be useful to both investors and policy makers (Salisu \& Oloko, 2015). Motivated by this research, in this paper we hypothesize that the oil and gold markets are asymmetrically related by their shocks on each other. Specifically, this study examines the asymmetric spillover effects in these two important commodity markets during the COVID-19 pandemic.

We first employ a vector autoregressive (VAR) model to test the mean spillover effects. The results suggest that the mean spillover effect is one way and there is no immediate return spillover effect from the gold market to the oil market. We use the Baba-Engle-Kraft-Kroner asymmetric generalized autoregressive conditional heteroskedasticity (BEKK-AGARCH) model to estimate the volatility spillover effects and find that a negative information shock in the oil market has a large impact on gold return volatility compared to a positive shock, suggesting that the effect is asymmetric. We show that the spillover effect from the oil to the gold market is stronger during the COVID-19 pandemic. Our study therefore contributes to the literature on gold-oil spillover effects by exploring not only the asymmetric nature of the relation between the two markets, but also how the pandemic has intensified the relation between the markets. This work thus adds to the broad and growing number of studies on COVID-19 (Narayan, 2021; Padhan \& Prabheesh, 2021).

\section{Methodology}

First, a conditional $\operatorname{VAR}(p)$ model is proposed to exam- 


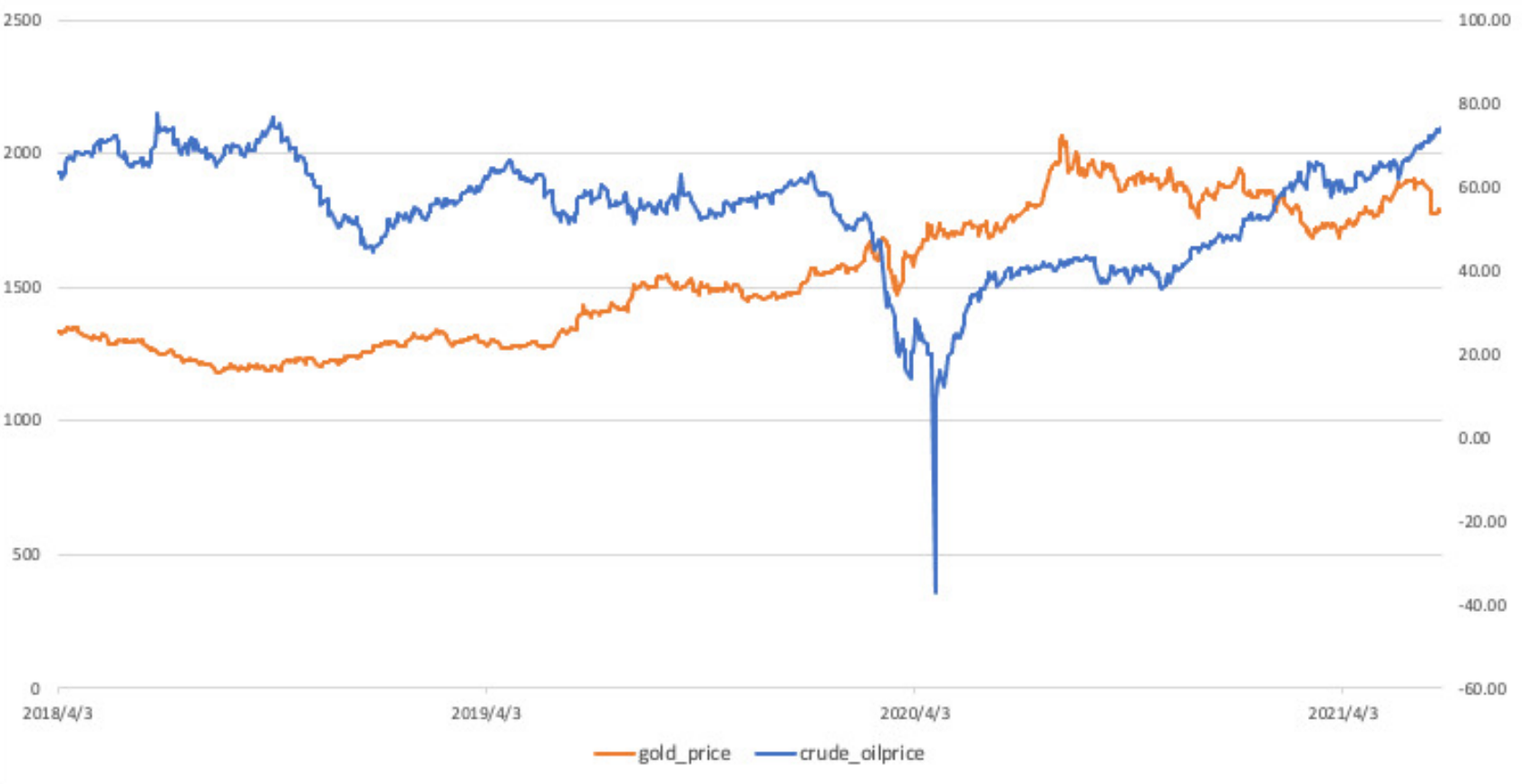

\section{Figure 1. Daily oil and gold price between 2018 and 2021}

This figure shows the time-series daily prices of gold and West Texas Intermediate (WTI) crude oil prices for the period April 3, 2018 to June 25, 2021. The data are sourced from the US Energy Information Administration and world gold council websites, see https://www.gold.org/cn/goldhub/data/gold-prices and https://www.eia.gov/.

ine the mean spillover effects between gold and oil price returns $\left(r_{i, t}\right)$, with the following specification:

$$
R_{t}=\alpha+\sum_{k=1}^{p} \beta_{k} R_{t-k}+\varepsilon_{t}
$$

where

$R_{t}=\left(r_{\text {oil }, t}, r_{\text {gold }, t}\right)^{\prime}$, with $r_{\text {oil }, t}$ and $r_{\text {gold }, t}$ being the returns on the crude oil and gold markets, respectively, at time $t$;

$\beta_{k}$ is a $(2 \times 2)$ matrix of coefficients of the form $\beta_{k}=\left(\begin{array}{ll}\beta_{11} & \beta_{12} \\ \beta_{21} & \beta_{22}\end{array}\right) ;$ and

$\varepsilon_{t}=\left(\varepsilon_{\text {oil }, t}, \varepsilon_{\text {gold }, t}\right)^{\prime \prime}$, with $\varepsilon_{\text {oil }, t}$ and $\varepsilon_{\text {gold,t }}$ being the error terms from the mean equations for the oil and gold market returns, respectively, which has a conditional covariance matrix $H_{t}$, given the available information set $I_{t-1}$.

When $\beta_{\mathrm{ij}}, i \neq j$, is significantly different from zero, we can expect market $i$ to have a mean spillover effect on market $j$. The best lagged term $p$ is chosen based on the Akaike information, final prediction error, and Bayesian information criteria.

In terms of the conditional variance-covariance equations, we utilize the unrestricted BEKK-AGARCH $(1,1)$ model, following Engle and Kroner (1995) and Salisu and Oloko (2015), to explore the volatility spillover effect. This AGARCH model allows for the interaction among the conditional variances and covariances across several time series. In addition, it incorporates the asymmetric effect coefficients to help us identify the different effects of positive and negative shocks. The conditional covariance-variance equation is expressed as follows:

$$
\begin{aligned}
H_{t}= & M^{\prime} M+A^{\prime} \varepsilon_{t-1} \varepsilon_{t-1}^{\prime} A+B^{\prime} H_{t-1} B \\
& +C^{\prime} I_{t-1} \varepsilon_{t-1} \varepsilon_{t-1}^{\prime} C
\end{aligned}
$$

where $M, A, B$, and $C$ are square matrices; $H_{t}$ is the conditional variance-covariance matrix, which represents mar- ket volatility; and $I_{t-1}$ is a function of the error term. Specifically, we have

$H_{t}=\left[\begin{array}{ll}h_{11, t} & h_{12, t} \\ h_{21, t} & h_{22, t}\end{array}\right]$, where $h_{i i, t}$ is the conditional variance of market $i$ at time $t$ and the off-diagonal elements $h_{i j, t}(i \neq j)$ represent the conditional covariance between market $i$ and $j$ at time $t$; $M=\left[\begin{array}{cc}m_{11} & 0 \\ m_{21} & m_{22}\end{array}\right]$, which is a lower triangular matrix to ensure the positive definiteness of $H_{t}$ (Bekiros, 2014); $A=\left[\begin{array}{ll}a_{11} & a_{12} \\ a_{21} & a_{22}\end{array}\right]$, whose elements are the coefficients of the ARCH term, showing the effects of the volatility in the market in question and the volatility spillover from the other market on the conditional volatility of the specified market; $B=\left[\begin{array}{ll}b_{11} & b_{12} \\ b_{21} & b_{22}\end{array}\right]$, whose elements represent the coefficients of the GARCH term, showing the effect of past volatility in the market in question and past volatility from the other market on the conditional volatility of the specified market; $C=\left[\begin{array}{ll}c_{11} & c_{12} \\ c_{21} & c_{22}\end{array}\right]$, whose elements indicate the coefficients of the asymmetric effect, where we do not expect the positive and negative shocks to have the same effects on the conditional volatility; and $I_{t-1}=\left[\begin{array}{cc}I_{\mathrm{oil}, t-1} & 0 \\ 0 & I_{\text {gold,t-1 }}\end{array}\right]$ where $I_{\mathrm{oil}, t-1}$ and $I_{i, t-1}=\left\{\begin{array}{l}0, \varepsilon_{i, t}>0 \\ 1, \varepsilon_{i, t} \leq 0\end{array}\right.$ for the $i$ th market at time $t$.

Note that the interpretation of the estimated coefficient based on the variance and covariance matrix is not easy. Therefore, the conditional variance for each equation can be expanded as follows: 


$$
\begin{aligned}
& h_{11, t}=m_{11}^{2}+a_{11}^{2} \varepsilon_{\mathrm{oil}, t-1}^{2} \\
& +a_{21}^{2} \varepsilon_{\text {gold }, t-1}^{2}+2 a_{11} a_{21} \varepsilon_{o i l, t-1} \varepsilon_{\text {gold }, t-1} \\
& +c_{11}^{2} \varepsilon_{\text {oil }, t-1}^{2} I_{\text {oil }, t-1}+c_{21}^{2} \varepsilon_{\text {gold }, t-1}^{2} I_{\text {oil }, t-1} \\
& +2 c_{11} c_{21} \varepsilon_{\text {oil }, t-1} \varepsilon_{\text {gold }, t-1} I_{\text {oil }, t-1}+b_{11}^{2} h_{11, t-1} \\
& +b_{21}^{2} h_{22, t-1}+2 b_{11} a_{21} h_{21, t-1} \\
& h_{22, \mathrm{t}}=m_{22}^{2}+a_{12}^{2} \varepsilon_{\mathrm{oil}, \mathrm{t}-1}^{2} \\
& +a_{22}^{2} \varepsilon_{\text {gold ,t-1 }}^{2}+2 a_{12} a_{22} \varepsilon_{\text {oil ,t- } 1} \varepsilon_{\text {gold ,t-1 }} \\
& +c_{12}^{2} \varepsilon_{\text {oil ,t }-1}^{2} I_{\text {oil ,t-1 }}+c_{22}^{2} \varepsilon_{\text {gold }, t-1}^{2} I_{\text {oil }, t-1} \\
& +2 c_{12} c_{22} \varepsilon_{\text {oil } t-1} \varepsilon_{\text {gold }, t-1} I_{\text {oil }, t-1}+b_{12}^{2} h_{11, t-1} \\
& +b_{22}^{2} h_{22, t-1}+2 b_{12} a_{22} h_{21, t-1} \\
& h_{21, t}=m_{21} m_{22}+a_{11} a_{22} \varepsilon_{\text {oil }, t-1}^{2}+a_{21} a_{22} \varepsilon_{\text {gold }, t-1}^{2} \\
& +\left(a_{21} a_{12}+a_{11} a_{22}\right) \varepsilon_{\text {oil }, t-1} \varepsilon_{\text {gold }, t-1} \\
& +c_{11} c_{22} \varepsilon_{\text {oil }, t-1}^{2} I_{\text {oil } t-1} \\
& +c_{21} c_{22} \varepsilon_{\text {gold }, t-1}^{2} I_{\text {oil }, t-1} \\
& +\left(c_{21} c_{12}+c_{11} c_{22}\right) \varepsilon_{\text {oil } t-1} \varepsilon_{\text {gold }, t-1} I_{\text {oil }, t-1} \\
& +b_{11} b_{22} h_{11, t-1}+b_{21} b_{22} h_{22, t-1} \\
& +\left(b_{21} b_{12}+b_{11} b_{22}\right) h_{21, t-1}
\end{aligned}
$$

To be specific, Eqs. (3) and (4) indicate how shocks and volatility are transmitted within the market in question over time, while Eq. (5) indicates the volatility spillover across different markets.

\section{Data}

The dataset in our study covers two variables, crude oil prices and gold prices. NYMEX WTI is used to proxy for international crude oil prices, because of its high liquidity and pricing transparency. We employ the price for XAUUSD contracts to represent gold prices, since its trading volume is the largest in the world. The time period is from June 27, 2018, to June 25, 2021. The full sample is further divided into two subsamples, with the subperiod prior to the COVID-19 pandemic (from June 27, 2018, to December 30, 2019) and the COVID-19 subperiod (from December 30, 2019 , to June 25,2021 ) subperiod. All daily trading data are collected from the websites of the US Energy Information Administration ${ }^{1}$ and the World Gold Council. ${ }^{2}$ Both the oil and gold prices are quoted in US dollars and the return series $\left(r_{i, t}\right)$ are calculated as follows:

$$
r_{i, t}=\ln P_{i, t}-\ln P_{i, t-1}
$$

where $P_{i, t}$ is the $i$ th (gold or oil) market price at time $t$, and $r_{i, t}$ is the $i$ th market return at time $t$. After eliminating missing values, we obtain a final full sample of 751 observations.

\section{Empirical results}

Table 1 shows the summary statistics for the two variables. The oil returns are more volatile than the gold returns, both during the full sample period and in the subperiods. According to the kurtosis statistic, the oil returns have fatter tails than the gold returns, and oil is thus risker. The Jarque-Bera results suggest that neither return follows a normal distribution, which is consistent with the kurtosis and skewness statistics. The Ljung-Box Q-statistics at both the 10th and 20th lags show that both return series display serial correlation at the $5 \%$ level of significance. Therefore, both returns exhibit conditional heteroscedasticity and ARCH effects. Additionally, augmented Dickey-Fuller and Phillips-Perron statistics suggest that all the series are stationary at the $1 \%$ level of significance. In conclusion, the VAR-BEKK-AGARCH $(1,1)$ model can be applied in our study. 
Table 1. Descriptive statistics of oil and gold price returns

\begin{tabular}{|c|c|c|c|c|c|c|c|c|c|c|c|}
\hline & Variables & $\mathrm{N}$ & Mean & SD & Min & Max & Skewness & Kurtosis & Jarque-Bera & ADF & PP test \\
\hline \multirow{2}{*}{$\begin{array}{l}\text { A: full-sample } \\
07 / 27 / 2018 \\
06 / 25 / 2021\end{array}$} & $r_{\text {oil }}$ & 751 & 0.00191 & 0.029 & -0.281 & 0.426 & 0.995 & 36.897 & $190000^{* * *}$ & $-65.32344^{* * *}$ & $-65.270^{* * *}$ \\
\hline & $r_{\text {gold }}$ & 751 & 0.00232 & 0.012 & -0.096 & 0.068 & -0.379 & 8.151 & $4394^{* * *}$ & $-62.749^{* * *}$ & $-62.764^{* * *}$ \\
\hline \multirow{2}{*}{$\begin{array}{l}\text { B: prior-COVID-19 } \\
07 / 27 / 2018 \\
12 / 30 / 2019\end{array}$} & $r_{\text {oil }}$ & 375 & 0.00223 & 0.093 & -1.000 & 0.999 & 0.204 & 74.046 & $79000^{* * *}$ & $-22.887^{* * *}$ & $-23.962^{* * *}$ \\
\hline & $r_{\text {gold }}$ & 375 & 0.00143 & 0.012 & -0.053 & 0.051 & -0.613 & 6.83 & $252^{* * *}$ & $-19.854^{* * *}$ & $-19.857^{* * *}$ \\
\hline \multirow{2}{*}{$\begin{array}{l}\text { C: COVID-19 } \\
12 / 30 / 2019 \\
06 / 25 / 2021\end{array}$} & $r_{\text {oil }}$ & 376 & -0.00029 & 0.024 & -0.128 & 0.164 & 0.135 & 7.685 & $3229^{* * *}$ & $-61.185^{* * *}$ & $-61.224^{* *}$ \\
\hline & $r_{\text {gold }}$ & 376 & 0.00112 & 0.012 & -0.096 & 0.068 & -0.353 & 8.312 & $4207^{* *}$ & $-59.471^{* * *}$ & $-59.474^{* * *}$ \\
\hline
\end{tabular}

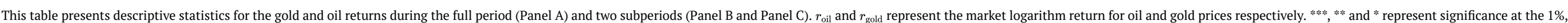
$5 \%$ and $10 \%$ levels, respectively. 
Table 2. Estimation result for VAP(p) model

\begin{tabular}{clll}
\hline & A: full-sample & B: prior-COVID-19 & C: COVID-19 \\
& $\mathbf{0 7 / 2 7 / 2 0 1 8}$ & $\mathbf{0 7 / 2 7 / 2 0 1 8}$ & $\mathbf{1 2 / 3 0 / 2 0 1 9}$ \\
& $\mathbf{0 6 / 2 5 / 2 0 2 1}$ & $\mathbf{1 2 / 3 0 / 2 0 1 9}$ & $\mathbf{0 6 / 2 5 / 2 0 2 1}$ \\
\hline $\boldsymbol{\alpha}$ & -0.00023 & -0.00041 & 0.0234 \\
$\boldsymbol{\beta}_{11,1}$ & $-0.00435^{* *}$ & $-0.00231^{* * *}$ & $-0.00591^{* * *}$ \\
$\boldsymbol{\beta}_{12,1}$ & $0.00543^{* * *}$ & $0.00031^{* *}$ & $0.04398^{* * *}$ \\
$\boldsymbol{\beta}_{21,1}$ & -0.03214 & -0.00087 & -0.06983 \\
$\boldsymbol{\beta}_{22,1}$ & $-0.28319^{* *}$ & $-0.01248^{* * *}$ & $-0.87745^{* * *}$ \\
$\boldsymbol{\beta}_{11,2}$ & -0.15323 & -0.24103 & -0.09248 \\
$\boldsymbol{\beta}_{12,2}$ & $0.00658^{* * *}$ & $0.00194^{* * *}$ & $0.07815^{* * *}$ \\
$\boldsymbol{\beta}_{21,2}$ & -0.00983 & -0.02047 & -0.02941 \\
$\boldsymbol{\beta}_{22,2}$ & $-0.00865^{* *}$ & $-0.00915^{* *}$ & $-0.01302^{* * *}$ \\
\hline
\end{tabular}

This table presents the result for VAR (p) model. Based on criteria, the best lagged term is 2 . Therefore, there are two estimation matrices for $\beta_{k}$. $* * * * * *$ and $*$ represent significance at the $1 \%, 5 \%$ and $10 \%$ levels, respectively.

\subsection{Mean equation analysis}

The estimation for the $\operatorname{VAR}(p)$ model requires setting the lag length $p$, for which we use the Akaike information and Bayesian information criteria. The optimal lag turns out to be two. Table 2 presents the results for the mean equation, which illustrate the shock and return spillover effects. It is evident that both the gold and oil returns are negatively affected by their own past shocks at the $5 \%$ level of significance, based on the negative and significant estimates of $\beta_{11,1}, \beta_{11,2}, \beta_{22,1}$, and $\beta_{22,2}$. As for the cross-market spillover effect, the oil market has a positive and significant return spillover effect on the gold market for the three periods, implied by the coefficients of $\beta_{12,1}$ and $\beta_{12,2}$. This spillover effect is intensified during the COVID-19 pandemic, since the coefficients of $\beta_{12,1}$ and $\beta_{12,2}$ are larger during the pandemic period. However, our study reveals that the oil market returns are not affected by past shocks to gold market returns, as evidenced by the nonsignificant coefficients of $\beta_{21,1}$ and $\beta_{21,2}$. In other words, there is no immediate return spillover effect from the gold market to the oil market. Our result is consistent with that of Salisu et al. (2021).

\subsection{Conditional variance-covariance equation analysis}

Table 3 presents the BEKK-AGARCH $(1,1)$ estimation results, evaluating the shock and volatility spillover effects between the markets. As mentioned above, the diagonal coefficients in the matrices $A$ and $B$ capture the market's own ARCH and GARCH effects. The significant coefficients of $a_{\mathrm{ii}}$ and $b_{\mathrm{ii}}$ across all three periods indicate that the volatilities of both the gold and oil markets are affected by their own past shocks and volatility. Notably, the ARCH and GARCH effects are magnified during the COVID-19 period for both markets.

The off-diagonal elements of the matrices $A$ and $\mathrm{B} \backslash$ measure the shock and volatility spillover effects across the markets. The current conditional volatility of the gold mar- ket will be affected by both the conditional variance $\left(b_{12}^{2}\right)$ and lagged shocks $\left(a_{12}^{2}\right)$ of the oil market before COVID-19. This result is consistent with the work of (Ewing \& Malik, 2013). One of the possible reasons is that the volatility spillover effect from the oil market to the gold market increases during the COVID-19 pandemic, given the larger positive and significant coefficient of $b_{12}^{2}$. However, no volatility or shock spillover effects from the gold market to the oil market are observed, given the nonsignificant coefficients of $b_{21}^{2}$ and $a_{21}^{2}$. Therefore, the volatility spillover effect is from the oil to the gold market and not from the gold to the oil market, which means that shocks to the oil market are more important for the gold market than shocks to the gold market are for the oil market. This finding could be due to the crude oil market being the largest commodity market in the world, and its volatility thus has a greater impact on the gold market.

Finally, the elements in matrix $C$ represent asymmetric spillover effects in the market. A negative shock in the market results in larger volatility in the market in question compared to positive shocks, implying that the shocks are asymmetric. This result is widely observed in many financial asset markets. These effects are more pronounced during the COVID-19 period. In addition, a negative shock in the oil market leads to greater volatility in the gold market than a positive shock, since $c_{12}^{2}$ is significantly different from zero.

Our model diagnostic test results in Table 3 suggest the robustness of the results, based on the Akaike information criterion, and the log-likelihood statistics suggest that our estimated BEKK-AGARCH $(1,1)$ model is well specified, reflecting the robustness of our model.

\section{Conclusion}

This study investigates the spillover effects between the international gold and oil markets. Using daily return data from June 27, 2018, to June 25, 2021, we employ a VAR(p)BEKK-AGARCH $(1,1)$ model to test whether there is an 
Table 3. Estimation result for BEKK-AGARCH $(1,1)$ model

\begin{tabular}{|c|c|c|c|}
\hline & $\begin{array}{l}\text { A: full-sample } \\
07 / 27 / 2018 \\
06 / 25 / 2021\end{array}$ & $\begin{array}{l}\text { B: prior-COVID-19 } \\
07 / 27 / 2018 \\
12 / 30 / 2019\end{array}$ & $\begin{array}{l}\text { C: COVID-19 } \\
12 / 30 / 2019 \\
06 / 25 / 2021\end{array}$ \\
\hline $\mathrm{m}_{11}$ & $0.1571^{* *}$ & 0.1968 & 0.1980 \\
\hline $\mathrm{m}_{21}$ & 0.0132 & $0.1791^{* *}$ & $0.3241^{* *}$ \\
\hline $\mathrm{m}_{22}$ & 0.1821 & $-1.20 \mathrm{E}-07$ & $3.90 \mathrm{E}-07$ \\
\hline$a_{11}$ & $-0.0023^{* * *}$ & $-0.7152^{* * *}$ & $0.1352^{* * *}$ \\
\hline$a_{12}$ & $0.0018^{* *}$ & $-0.02991^{* * *}$ & $0.9017^{* * *}$ \\
\hline $\mathrm{a}_{21}$ & -0.1459 & 0.2549 & -0.3819 \\
\hline$a_{22}$ & $-0.1483^{* * *}$ & $0.1990^{* * *}$ & $-0.3196^{* * *}$ \\
\hline$b_{11}$ & $-0.0042^{* * *}$ & $0.0049^{* *}$ & $0.2415^{* * *}$ \\
\hline$b_{12}$ & $-0.0037^{* * *}$ & $0.0049^{* * *}$ & $0.2373^{* * *}$ \\
\hline$b_{21}$ & -0.7831 & -0.7329 & -2.3272 \\
\hline$b_{22}$ & $-0.7851^{* * *}$ & $-0.8341^{* *}$ & $-2.255^{* * *}$ \\
\hline$c_{11}$ & $0.5910^{* * *}$ & $0.0732^{* * *}$ & $0.9871^{* * *}$ \\
\hline$c_{12}$ & $-0.0061^{* * *}$ & $-0.0022^{* *}$ & $0.1133^{* * *}$ \\
\hline$c_{21}$ & 0.3013 & 0.5762 & 0.4539 \\
\hline$c_{22}$ & $0.9130^{* * *}$ & $0.7282^{* * *}$ & $0.5243^{* * *}$ \\
\hline \multicolumn{4}{|c|}{ Model diagnostics } \\
\hline AIC & 6.982 & 7.193 & 4.948 \\
\hline Log-L & -62734.139 & -10731.193 & -43612.573 \\
\hline
\end{tabular}

The table represents the estimation result for BEKK-AGARCH $(1,1)$ model, ${ }^{* * * * * * * *}$ and * represent significance at the $1 \%, 5 \%$ and $10 \%$ levels, respectively.

asymmetric spillover effect between the gold and oil markets and explore how this effect changes during the COVID-19 pandemic. Our results show no bidirectional return or volatility spillover effects between the gold and oil markets during the COVID-19 pandemic. Only a shock or volatility in the oil market leads to conditional volatility in the gold market, whereas the gold market's volatility has no significant effects on the oil market. In addition, the spillover effect from the oil market to the gold market is amplified during the COVID-19 pandemic.

Second, both the oil and gold markets exhibit asymmetric spillover effects, such that a negative information shock has a large impact on market volatility. Moreover, a negative information shock in the oil market leads to greater volatility in the gold market than a positive shock. Our research analyzes how the COVID-19 pandemic influences the spillover effects between the gold and oil markets. Our paper also examines the asymmetric spillover effects between the gold and oil markets under the BEKK model. Further research could be conducted in terms of the asymmetric spillover effects among more asset markets, such as the exchange rate and commodity markets. 


\section{REFERENCES}

Atri, H., Kouki, S., \& Gallali, M. i. (2021). The impact of COVID-19 news, panic and media coverage on the oil and gold prices: An ARDL approach. Resources Policy, 72. https://doi.org/10.1016/j.resourpol.2021.102061

Bampinas, G., \& Panagiotidis, T. (2015). On the relationship between oil and gold before and after financial crisis: Linear, nonlinear and time-varying causality testing. Studies in Nonlinear Dynamics \& Econometrics, 19(5), 657-668. https://doi.org/10.1515/ snde-2014-0060

Baur, D. G., \& McDermott, T. K. (2010). Is gold a safe haven? International evidence. Journal of Banking \& Finance, 34(8), 1886-1898. https://doi.org/10.1016/i.j bankfin.2009.12.008

Bekiros, S. D. (2014). Contagion, decoupling and the spillover effects of the US financial crisis: Evidence from the BRIC markets. International Review of Financial Analysis, 33, 58-69. https://doi.org/10.1016/ j.irfa.2013.07.007

Chen, Y., \& Qu, F. (2019). Leverage effect and dynamics correlation between international crude oil and China's precious metals. Physica A: Statistical Mechanics and Its Applications, 534, 122319. https://d oi.org/10.1016/i.physa.2019.122319

Dutta, A., Das, D., Jana, R. K., \& Vo, X. V. (2020). COVID-19 and oil market crash: Revisiting the safe haven property of gold and Bitcoin. Resources Policy, 69. https://doi.org/10.1016/j.resourpol.2020.101816

Ewing, B. T., \& Malik, F. (2013). Volatility transmission between gold and oil futures under structural breaks. International Review of Economics \& Finance, 25, 113-121. https://doi.org/10.1016/j.iref.2012.06.008

Gharib, C., Mefteh-Wali, S., \& Jabeur, S. B. (2021). The bubble contagion effect of COVID-19 outbreak: Evidence from crude oil and gold markets. Finance Research Letters, 38, 101703. https://doi.org/10.1016/ j.frl.2020.101703

Kang, S. H., McIver, R., \& Yoon, S.-M. (2017). Dynamic spillover effects among crude oil, precious metal, and agricultural commodity futures markets. Energy Economics, 62, 19-32. https://doi.org/10.1016/j.enec $\underline{0.2016 .12 .011}$
Lau, M. C. K., Vigne, S. A., Wang, S., \& Yarovaya, L. (2017). Return spillovers between white precious metal ETFs: The role of oil, gold, and global equity. International Review of Financial Analysis, 52, 316-332. https://doi.org/10.1016/i.irfa.2017.04.001

Narayan, P. K. (2021). Understanding exchange rate shocks during COVID-19. Finance Research Letters, 102181. https://doi.org/10.1016/j.frl.2021.102181

Padhan, R., \& Prabheesh, K. P. (2021). The economics of COVID-19 pandemic: A survey. Economic Analysis and Policy, 70, 220-237. https://doi.org/10.1016/j.eap.202 1.02.012

Reboredo, J. C. (2013). Is gold a hedge or safe haven against oil price movements? Resources Policy, 38(2), 130-137. https://doi.org/10.1016/j.resourpol.2013.0 2.003

Ross, S. A. (1989). Information and Volatility: The NoArbitrage Martingale Approach to Timing and Resolution Irrelevancy. The Journal of Finance, 44(1), 1-17. https://doi.org/10.1111/j.1540-6261.1989.tb024 $\underline{01 . x}$

Salisu, A. A., \& Oloko, T. F. (2015). Modeling oil price-US stock nexus: A VARMA-BEKK-AGARCH approach. Energy Economics, 50, 1-12. https://doi.org/ 10.1016/i.eneco.2015.03.031

Salisu, A. A., Raheem, I. D., \& Vo, X. V. (2021). Assessing the safe haven property of the gold market during COVID-19 pandemic. International Review of Financial Analysis, 74. https://doi.org/10.1016/j.irfa.20 21.101666

Shahbaz, M., Balcilar, M., \& Abidin Ozdemir, Z. (2017). Does oil predict gold? A nonparametric causality-inquantiles approach. Resources Policy, 52, 257-265. htt ps://doi.org/10.1016/j.resourpol.2017.03.004

Yaya, O. S., Tumala, M. M., \& Udomboso, C. G. (2016). Volatility persistence and returns spillovers between oil and gold prices: Analysis before and after the global financial crisis. Resources Policy, 49, 273-281. $\underline{\mathrm{h}}$ ttps://doi.org/10.1016/i.resourpol.2016.06.008 